Chemical Physics Letters, in press.

\title{
Direct synthesis of high-quality single-walled carbon nanotubes on silicon and quartz substrates
}

\author{
Yoichi Murakami, Yuhei Miyauchi, Shohei Chiashi, Shigeo Maruyama* \\ Department of Mechanical Engineering, The University of Tokyo \\ 7-3-1 Hongo, Bunkyo-ku, Tokyo 113-8656, Japan
}

Received 25 April 2003; in final form 29 May 2003

\begin{abstract}
A new technique of synthesizing high-quality single-walled carbon nanotubes (SWNTs) directly on the surface of silicon and quartz substrates has been developed by means of the low-temperature catalytic CVD method using ethanol. The proposed method does not employ conventional deposition/sputtering for the mounting of catalytic metals on the substrates, but it adopts an easy and costless liquid-based dip-coat approach without need of support/underlayer materials that were often used in previous studies. The substrate surface is blackened with a uniform layer of SWNTs after the CVD at an optimum condition. The optical absorption of 'as-grown' SWNTs has first been measured using thereby prepared SWNT-synthesized quartz substrate.
\end{abstract}

*Corresponding Author. Fax: +81-3-5800-6983.

E-mail address: maruyama@photon.t.u-tokyo.ac.jp (S. Maruyama). 
Chemical Physics Letters, in press.

\section{Introduction}

The discovery of single-walled carbon nanotubes (SWNTs) [1] followed by the landmark establishment of their macroscopic generation method [2] has motivated numerous attempts to explore this newly-found exciting carbon allotrope. Concerning many proposed applications utilizing the unique physical properties of SWNTs [3], an appropriate incorporation of SWNTs into silicon or other material-based systems is essential for full appreciation of the outstanding nature of SWNTs.

Several trials have so far been made to synthesize carbon nanotubes onto these substrates using various approaches. Kong et al. [4] and Franklin et al. [5] spun-coated Fe/Mo catalyst with alumina support particles to form patterned catalytic islands on Si surfaces and synthesized a small amount of SWNTs. Cassell et al. [6] synthesized SWNTs on Si substrate with a similar technique but employed mesoporous alumina/silica as a support for Fe/Mo catalyst. In several other reports, mesoporous silica was employed as a support in the form of thin-film coated on Si surface to synthesize SWNTs [7] and MWNTs [8, 9]. In contrast to these studies that employed certain support materials, Li et al. [10] mounted iron nanoparticles utilizing the ferritin protein and sparsely produced $\mathrm{SWNTs}$ on a flat $\mathrm{SiO}_{2}$ substrate.

In other approaches, catalytic metals were mounted on the substrate using dry processes such as sputtering or deposition [11-15]; however, these methods often suffered from a production of multi-walled carbon nanotubes (MWNTs). Dominant products of Nerushev et al. [11] and Yoon et al. [12] were MWNTs, although they reported to have synthesized some SWNTs based on their Raman spectra of low S/N ratio. Delzeit et al. [13] synthesized SWNTs by depositing $20 \mathrm{~nm}$ of aluminum underlayer and $1 \mathrm{~nm}$ of Fe/Mo layer on a Si substrate. Hongo et al. [14] synthesized relatively high-quality SWNTs by depositing 2 to $5 \mathrm{~nm} \mathrm{Fe}$ on the A-face of sapphire crystal; 
Chemical Physics Letters, in press.

however, no SWNTs were produced when $\mathrm{Si}$ or $\mathrm{SiO}_{2}$ substrates were employed instead.

From the studies cited above, these deposition/sputter approaches are prone to accompany sintering of catalytic metals, as they often resulted in catalytic metal droplets of several tens of nanometers [12-14]. The sintering is partly caused by their higher temperature around 900 to 1000 ${ }^{\circ} \mathrm{C}$ to synthesize SWNTs on a Si substrate [4-6, 11-13]. In addition, Arcos et al. [15] demonstrated that the deposited $1 \mathrm{~nm}$ layer of $\mathrm{Fe}$ reacted with a Si substrate to form silicide at $850{ }^{\circ} \mathrm{C}$, by which catalytic activity was deteriorated. Such a high-temperature based approach inherently involves a dilemma because, when one attempts to synthesize SWNTs without a support material, one needs to prepare a thick underlayer (20 $\mathrm{nm}$ of $\mathrm{Al}$ or $\mathrm{Ir}$ [13] or $80 \mathrm{~nm}$ of TiN [15]) between the catalytic metal and the Si substrate to avoid silicide formation. However, the metallic underlayer itself can be sintered into a droplet at elevated temperature, leading to a surface roughness.

In the present report, SWNTs were synthesized directly (i.e. without support or underlayer) onto a substrate using a liquid-based approach for the catalytic mount, in combination with the low-temperature alcohol catalytic CVD method $[16,17]$, to circumvent aforementioned problems. The catalytic metal was specifically mounted by the so-called 'dip-coat' method, where the substrate was vertically drawn up from the metallic acetate solution at a constant speed, followed by heating to convert thereby mounted acetic metals into metal oxides.

\section{Preparations and Experiments}

A metal acetate solution was prepared first by dissolving molybdenum acetate $\left(\mathrm{CH}_{3} \mathrm{COOH}\right)_{2} \mathrm{Mo}$ and cobalt acetate $\left(\mathrm{CH}_{3} \mathrm{COOH}\right)_{2} \mathrm{Co}-4 \mathrm{H}_{2} \mathrm{O}$ into ethanol (typically $40 \mathrm{~g}$ ) so that the concentration of each metallic species was $0.01 \mathrm{wt} \%$ with sonication for $2 \mathrm{~h}$. Unlike our previous reports $[7,16,17]$, where Fe and Co were employed, Mo and Co were chosen after our findings in 
Chemical Physics Letters, in press.

several preliminary experiments: From our preliminary experiments, the Mo/Co catalyst seems to present better performances over the $\mathrm{Fe} / \mathrm{Co}$ catalyst at least in the tested range of metallic concentration and CVD conditions.

For a substrate, we employed either n-type Si wafer with (100)-surface (Nilaco Corp., SI-500452) or fused quartz with both sides optically polished (Fujitok Corp., \#19983); both substrates had a thickness of $0.5 \mathrm{~mm}$. The silicon substrate was cut into a strip of about $7 \times 20 \mathrm{~mm}^{2}$, while the size of $25 \times 25 \mathrm{~mm}^{2}$ was used for the quartz substrate. The choice of a larger dimension for quartz is based on the following optical measurements. These substrates were held by a small clip with a stabilizing weight and a nylon fishing line. The substrate piece was then submerged into a prepared metallic acetate solution for $10 \mathrm{~min}$, leaving upper $5 \mathrm{~mm}$ of it above the solution level to prevent the clip from contacting the solution. This piece was then drawn up from the solution at a constant speed of $4 \mathrm{~cm} / \mathrm{min}$. The surface of the substrate was rapidly dried at several millimeters above the liquid contact level as soon as it was removed from the solution. Right after this process, the piece was placed in a furnace maintained at $400{ }^{\circ} \mathrm{C}$ for $5 \mathrm{~min}$ in air to decompose acetates or any other organic residues to form an oxide of bimetallic Mo/Co catalyst. The decomposition of these metallic acetates below $400{ }^{\circ} \mathrm{C}$ was confirmed by TGA. Since no catalytic metals on the surface were detected with FE-SEM both before and after the CVD reaction, detailed characterization of the metals is currently in progress using AFM and TEM.

The detailed procedure in the subsequent CVD process was reported elsewhere $[16,17]$. In brief, a piece of the substrate was placed on a quartz boat, which was then set in a quartz tube inside an electric furnace. During the heat-up of the electric furnace, $\mathrm{Ar} / \mathrm{H}_{2}\left(3 \% \mathrm{H}_{2}\right)$ was supplied so that the pressure inside the quartz tube was $300 \pm 20$ Torr. When the desired temperature was reached, $\mathrm{Ar} / \mathrm{H}_{2}$ was stopped and inside of the quartz tube was evacuated by a rotary pump. Subsequently, ethanol vapor was supplied so that the pressure just before the entrance of the quartz tube was 
Chemical Physics Letters, in press.

maintained at 10 Torr. After the reaction, the electric furnace was turned off and cooled down to room temperature with a $100 \mathrm{sccm}$ flow of $\mathrm{Ar} / \mathrm{H}_{2}$. The use of hydrogen is for the reduction of $\mathrm{Mo} / \mathrm{Co}$ bimetal to retrieve its catalytic function, as demonstrated in our previous study [17]. The details were reported by Alvarez et al. [18], where reduction of Mo/Co bimetallic catalyst by hydrogen was studied.

The synthesized SWNTs were characterized by FE-SEM (Hitachi, S-900) and micro Raman scattering measurements (Chromex 501is and Andor DV401-FI for the spectrometer and CCD system, respectively with an optical system of Seki Technotron STR250). All the Raman spectra presented in this report were an arithmetic average of the measurements at randomly chosen 10 different locations on the substrate. The VIS-NIR absorption spectra were measured with Hitachi U-4000.

\section{Results and discussion}

The Raman spectra of SWNTs synthesized on Si and quartz substrates are presented in Fig. 1. The CVD reaction times were 10 and $60 \mathrm{~min}$ for $\mathrm{Si}$ and quartz, respectively. The amount of synthesized SWNTs was quantitatively compared using a height ratio of the G-band to the Si-derived peak at $518 \mathrm{~cm}^{-1}$ : The ratios were $0.07,0.23,5.2$, and 1.5 for the cases of $650,750,800$, and $850{ }^{\circ} \mathrm{C}$, respectively. No SWNTs were obtained in the synthesis at $900{ }^{\circ} \mathrm{C}$ (not shown). Therefore, the optimum temperature for maximizing the amount of SWNTs in the present study was estimated to be $800{ }^{\circ} \mathrm{C}$. The decrease in the amount above $850{ }^{\circ} \mathrm{C}$ probably results from the formation of silicide, as demonstrated by Arcos et al. [15] with their Fe catalyst. Note that the optimum synthesis temperature could be affected by the thickness of a natural oxidation layer on the surface of employed Si wafer, which was typically in the range of 0.5 to $10 \mathrm{~nm}$. We tested several Si wafers purchased from different sources and found that the optimum temperature was $750{ }^{\circ} \mathrm{C}$ for 
Chemical Physics Letters, in press.

some of the wafers, which produced smaller amounts of SWNTs above $800{ }^{\circ} \mathrm{C}$. At any temperature, sufficiently high quality of SWNTs was confirmed from their high G/D ratio (e.g. 30 at $800{ }^{\circ} \mathrm{C}$ ). The radial breathing mode (RBM) peaks were observed at all temperature. Note that the synthesis temperature of SWNTs on the Si substrate, $650{ }^{\circ} \mathrm{C}$, is by far the lower than any of the previous reports [4-6, 10-13], where $900 \sim 1000{ }^{\circ} \mathrm{C}$ was employed or needed for SWNT synthesis. The spectrum of the SWNTs synthesized on a quartz substrate at $800{ }^{\circ} \mathrm{C}$ indicates high enough quality, G/D ratio: 25 , despite the CVD exposure as long as $60 \mathrm{~min}$.

Figure 2 exhibits the RBM spectra of SWNTs synthesized on Si and quartz substrates at 800 ${ }^{\circ} \mathrm{C}$, measured by three different excitation wavelengths. The RBM spectrum of HiPco SWNTs [19, 20] (batch \#: HPR113.4) provided from Rice University is included for reference. The CVD reaction times were 10 and 60 min for $\mathrm{Si}$ and quartz, respectively. The Kataura plot [21] with $\gamma_{0}=$ $2.9 \mathrm{eV}$ and $\mathrm{a}_{\mathrm{c}-\mathrm{c}}=0.144 \mathrm{~nm}[22,23]$ is exhibited along with the horizontal lines corresponding to the laser excitation energies. The diameter $d$ of SWNTs was estimated from the RBM Raman shift $v$ using the relationship $d / \mathrm{nm}=248 /\left(v / \mathrm{cm}^{-1}\right)[22,23]$. The locations of measured Raman peaks agree well with those predicted by the Kataura plot, and a relatively narrow diameter distribution ranging $1.1-1.7 \mathrm{~nm}$ is recognized. It is also found that the diameter distribution of SWNTs on a quartz substrate is slightly thinner than that on a silicon substrate.

The SEM images of the SWNTs directly synthesized on $\mathrm{Si}$ and quartz substrates corresponding to Fig. 2 are shown in Fig. 3. The background dark area in Fig. 3(a) represents the surface of Si substrate, on which a uniform layer of web-like SWNT-bundles was observed. Figure 3(b) shows an SEM image taken from a slanted angle including the broken cross-section of the quartz substrate. Due to its longer reaction time of 60 min, a uniform SWNT 'mat' with a thickness of a few hundreds of nm was formed on the surface. This picture clearly displays a close-up view of the SWNT mat, where some of the bundles are seen to cascade into space from the broken edge. 
Chemical Physics Letters, in press.

Figure 4 further shows the TEM image of SWNTs corresponding to those in Fig. 3(b). A micro-grid was directly rubbed against the blackened quartz surface for TEM observation. We observed an edge of SWNT drapery on the micro-grid to assure the transmittance of the electron beam. Figure 4 evidences that our SWNTs are free from any metal particles, amorphous carbons, or multi-walled nanotubes.

Since the quartz substrates prepared by the present method looked blackened, their optical properties of 'as-grown' SWNTs can be readily measured. The optical absorbance of SWNTs synthesized under the conditions of $800{ }^{\circ} \mathrm{C}$ and $60 \mathrm{~min}$, corresponding to Fig. 3(b), is shown in Fig. 5. The substrate was cut in two and stacked together to double the absorption. The absorbance was recorded as a differential from that of a catalyst-mounted quartz that was almost transparent in the whole range of the measured wavelength. The pristine sample of HiPco SWNTs (batch \#: HPR113.4), sonicated and suspended in $\mathrm{D}_{2} \mathrm{O}$ (1\% SDS) without centrifuging, was measured for reference. The absorption spectrum of 'as-grown' SWNTs on the quartz substrate shows a tendency similar to that of the bundled HiPco sample, whose interpretation was described by O'Connell et al. [24]. By combination with the diameter distribution of current SWNTs (Fig. 2), the peaks around 1450 and $800 \mathrm{~nm}$ are found to correspond to the gap energies of semiconducting $\mathrm{E}_{11}^{\mathrm{S}}$ and $\mathrm{E}_{22}^{\mathrm{S}}$, respectively. The slight red shift of these features from the suspended HiPco sample is probably ascribable to the slightly larger average diameters of our samples, as shown in Fig. 2. This is the first report that measured the optical absorption of 'as-grown' SWNTs directly synthesized on the quartz substrate. Optical absorption of SWNTs on a substrate has conventionally been measured using samples prepared by sonicating bulk-produced SWNTs with methods such as laser furnace or HiPco and spraying the dispersed solution onto an optical substrate [21].

\section{Concluding Remarks}


Chemical Physics Letters, in press.

We have demonstrated that high-quality SWNTs can be synthesized directly on silicon and quartz substrates employing the dip-coating approach for the mounting of catalytic metals combined with the low-temperature alcohol CCVD method. The features of this liquid-based technique lie in its easy, costless, and versatile nature in addition to its easiness to mount a small amount of catalytic metals by using diluted metal acetate solution. This method can be applied toward solids of various geometries without necessitating deposition/sputtering devices. Authors foresee that this method will open up novel applications such as optical and sensing devices.

\section{Acknowledgement}

The authors thank Prof. R. E. Smalley at Rice University for his supply of the HiPco sample, Prof. T. Okubo and Mr. T. Sugawara at the University of Tokyo for allowing us to use their FE-SEM, and Mr. H. Tsunakawa at UT for his assistances in the operation of TEM. Part of this work was financially supported by KAKENHI \#12450082 and 13555050 from JSPS, and \#13GS0019 from MEXT. 
Chemical Physics Letters, in press.

\section{References}

[1] S. Iijima, T. Ichihara, Nature 363 (1993) 603.

[2] A. Thess, R. Lee, P. Nikolaev, H. Dai, P. Petit, J. Robert, C. Xu, Y.H. Lee, S.G. Kim, A.G. Rinzler, D.T. Colbert, G.E. Scuseria, D. Tománek, J.E. Fischer, R.E. Smalley, Science 273 (1996) 483.

[3] R. Saito, G. Dresselhaus, M.S. Dresselhaus, Physical Properties of Carbon Nanotubes, Imperial College Press, London, 1998.

[4] J. Kong, H.T. Soh, A.M. Cassell, C.F. Quate, H. Dai, Nature 395 (1998) 878.

[5] N.R. Franklin, Y. Li, R.J. Chen, A. Javey, H. Dai, Appl. Phys. Lett. 79 (2001) 4571.

[6] A.M. Cassell, N.R. Franklin, T.W. Tombler, E.M. Chan, J. Han, H. Dai, J. Am. Chem. Soc. $121(1999) 7975$.

[7] Y. Murakami, S. Yamakita, T. Okubo, S. Maruyama, Chem. Phys. Lett., in press.

[8] A.M. Cassell, S.Verma, L. Delzeit, M. Meyyappan, J. Han, Langmuir 17 (2001) 260.

[9] N. Petkov, S. Mintova, K. Karaghiosoff, T. Bein, Mat. Sci. Eng. C 23 (2003) 145.

[10] Y. Li, W. Kim, Y. Zhang, M. Rolandi, D. Wang, H. Dai, J. Phys. Chem. B 105 (2001) 11424.

[11] O.A. Nerushev, R.E. Morjan, D.I. Ostrovskii, M. Sveningsson, M. Jonsson, F. Rohmund, E.E.B. Campbell, Physica B 323 (2002) 51.

[12] Y.J. Yoon, J.C. Bae, H.K. Baik, S. Cho, S. Lee, K.M. Song, N.S. Myung, Chem. Phys. Lett. $366(2002) 109$.

[13] L. Delzeit, B. Chen, A. Cassell, R. Stevens, C. Nguyen, M. Meyyappan, Chem. Phys. Lett. $348(2001) 368$.

[14] H. Hongo, M. Yudasaka, T. Ichihashi, F. Nihey, S. Iijima, Chem. Phys. Lett. 361 (2002) 349.

[15] T. de los Arcos, F. Vonau, M.G. Garnier, V. Thommen, H.-G. Boyen, P. Oelhafen, M. Duggelin, D. Mathis, R. Guggenheim, Appl. Phys. Lett. 80 (2002) 2383. 
Chemical Physics Letters, in press.

[16] S. Maruyama, R. Kojima, Y. Miyauchi, S. Chiashi, M. Kohno, Chem. Phys. Lett. 360 (2002) 229.

[17] Y. Murakami, Y. Miyauchi, S. Chiashi, S. Maruyama, Chem. Phys. Lett. 374 (2003) 53.

[18] W.E. Alvarez, B. Kitiyanan, A. Borgna, D.E. Resasco, Carbon 39 (2001) 547.

[19] P. Nikolaev, M.J. Bronikowski, R.K. Bradley, F. Rohmund, D.T. Colbert, K.A. Smith, R.E. Smalley, Chem. Phys. Lett. 313 (1999) 91.

[20] M.J. Bronikowski, P.A. Willis, D.T. Colbert, K.A. Smith, R.E. Smalley, J. Vac. Sci. Technol. A $19(2001) 1800$.

[21] H. Kataura, Y. Kumazawa, Y. Maniwa, I. Umezu, S. Suzuki, Y. Ohtsuka, Y. Achiba, Synth. Met. 103 (1999) 2555.

[22] R. Saito, G. Dresselhaus, M.S. Dresselhaus, Phys. Rev. B 61 (2000) 2981.

[23] A. Jorio, R. Saito, J.H. Hafner, C.M. Lieber, M. Hunter, T. McClure, G. Dresselhaus, M.S. Dresselhaus, Phys. Rev. Lett. 86 (2001) 1118.

[24] M.J. O’Connell, S.M. Bachilo, C.B. Haffman, V.C. Moore, M.S. Strano, E.H. Haroz, K.L. Rialon, P.J. Boul, W.H. Noon, C. Kittrell, J. Ma, R.H. Hauge, R.B. Weisman, R.E. Smalley, Science 297 (2002) 593. 
Chemical Physics Letters, in press.

\section{Figure Captions}

Fig. 1. Raman spectra measured by $488 \mathrm{~nm}$ excitation of SWNTs synthesized on silicon and quartz substrates at various CVD temperatures.

Fig. 2. RBM spectra of SWNTs synthesized at $800^{\circ} \mathrm{C}$ on the surface of $\mathrm{Si}$ and quartz substrates, measured by 488, 514.5, and $633 \mathrm{~nm}$ excitations. 'HiPco' is the reference spectrum of a pristine HiPco sample measured by $488 \mathrm{~nm}$ excitation. The Kataura plot for the corresponding range is attached on the top, where solid and open circles denote semiconducting and metallic SWNTs, respectively.

Fig. 3. FE-SEM images of SWNTs synthesized on (a) silicon substrate taken from top and (b) quartz substrate taken from slanted angle. Both samples correspond to those shown in Fig. 2.

Fig. 4. TEM image of SWNTs directly grown on the quartz substrate. The sample corresponds to shown in Fig. 3(b).

Fig. 5. Optical absorbance of (a) 'as-grown' SWNTs directly synthesized on the surface of quartz substrate, and (b) the reference spectrum of the HiPco pristine sample sonicated and suspended in $\mathrm{D}_{2} \mathrm{O}$ with $1 \% \mathrm{SDS}$. 
Chemical Physics Letters, in press.

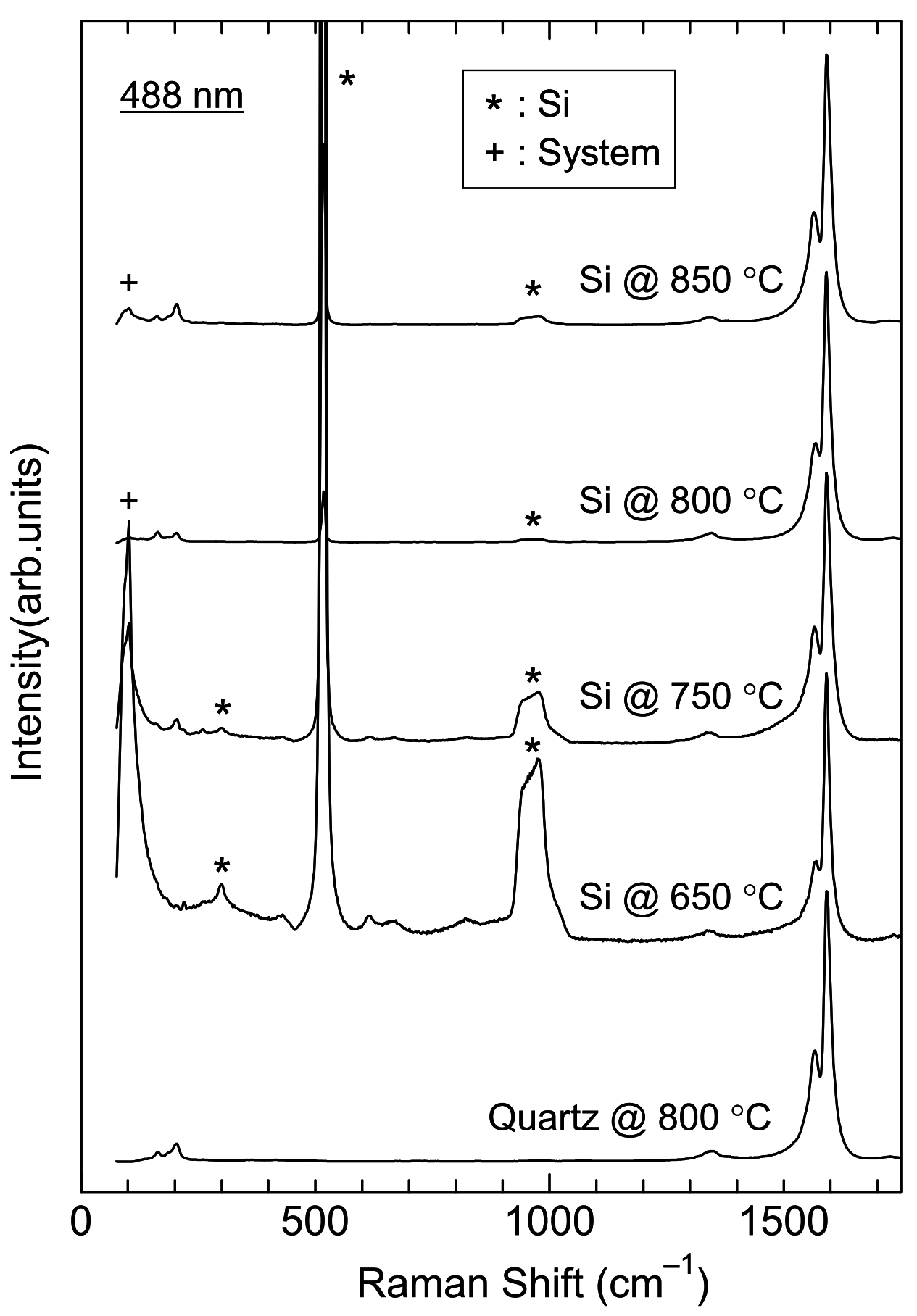

Fig. 1. 
Chemical Physics Letters, in press.

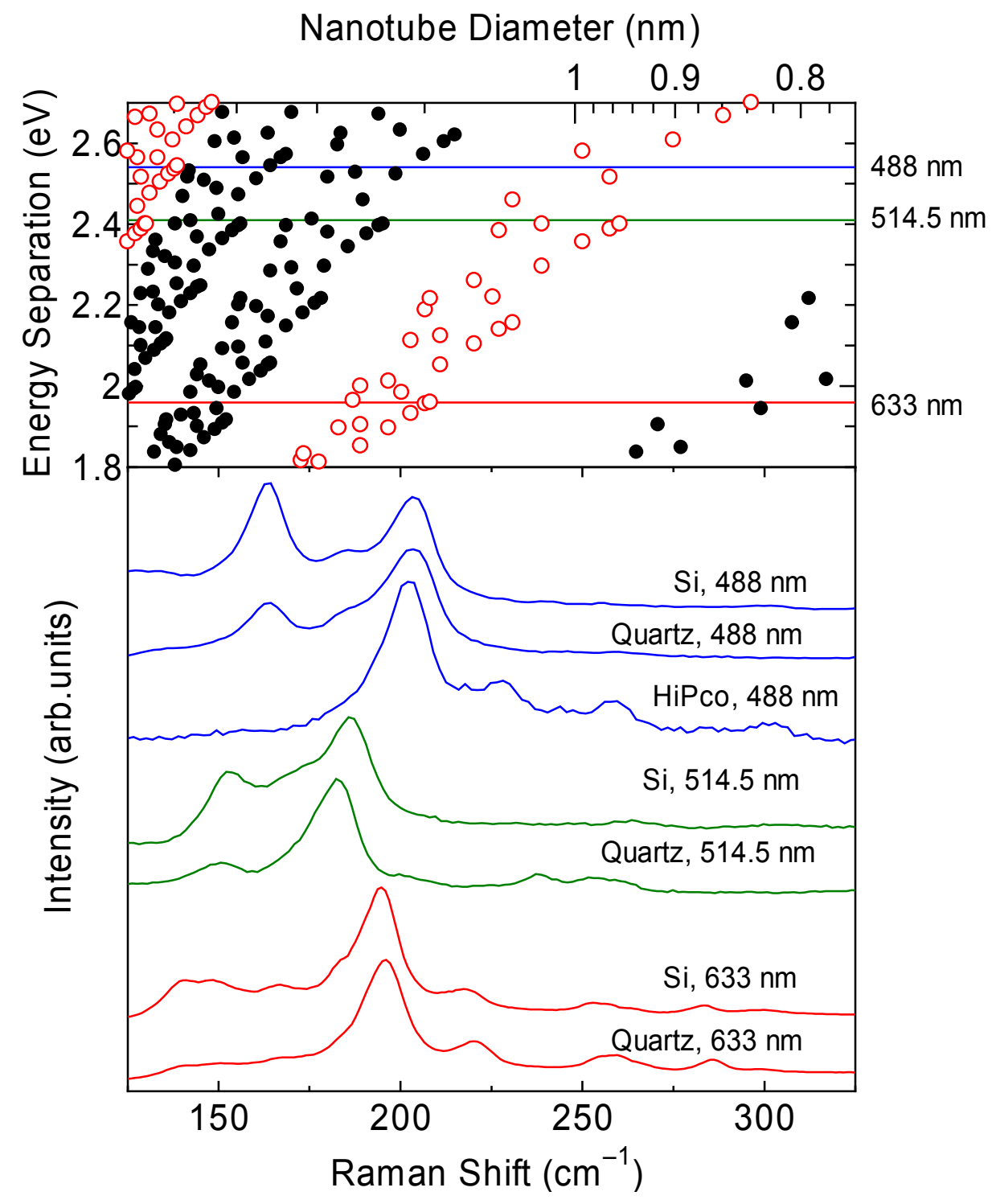

Fig. 2. 
Chemical Physics Letters, in press.

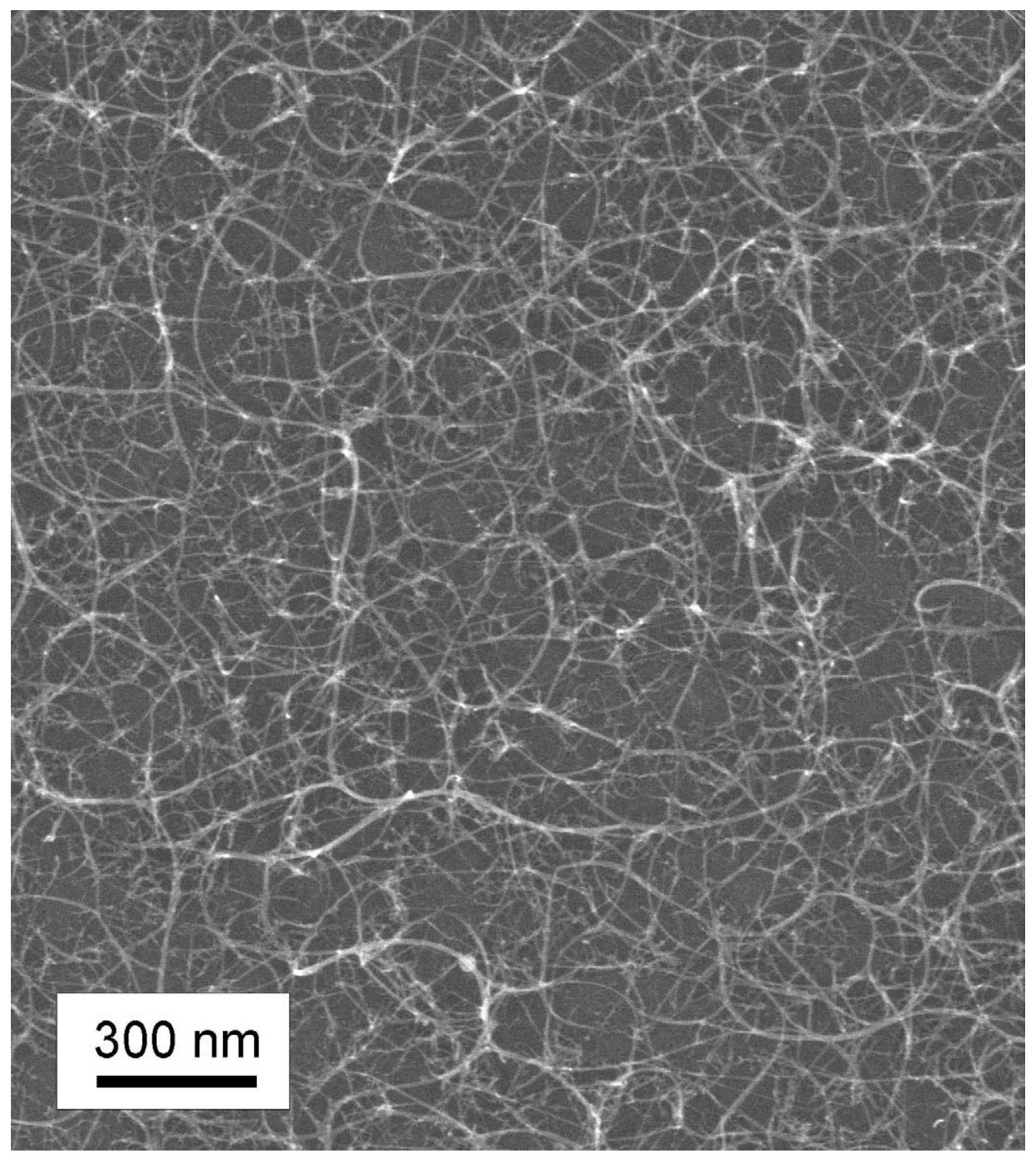

Fig. 3(a). 
Chemical Physics Letters, in press.

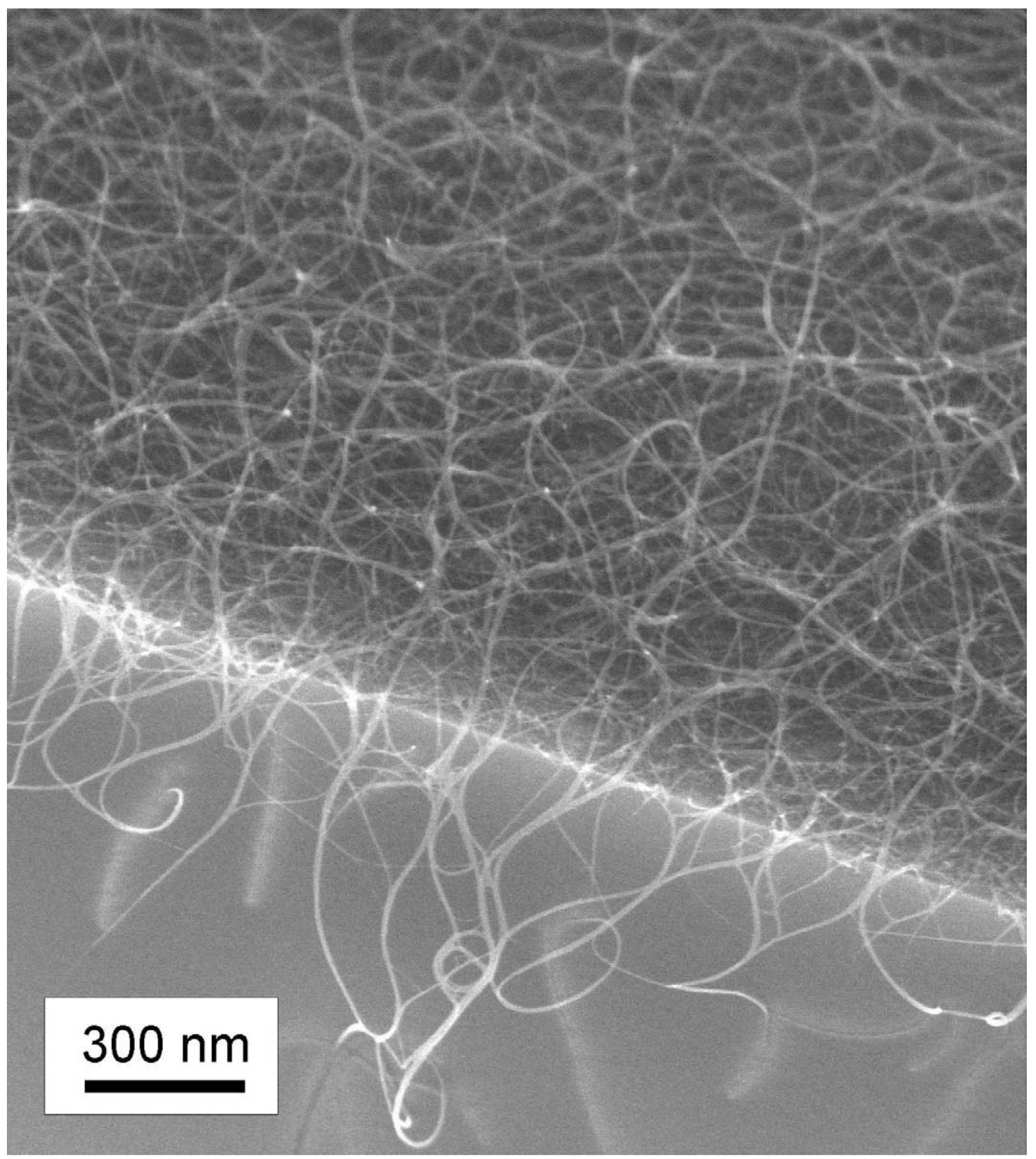

Fig. 3(b). 
Chemical Physics Letters, in press.

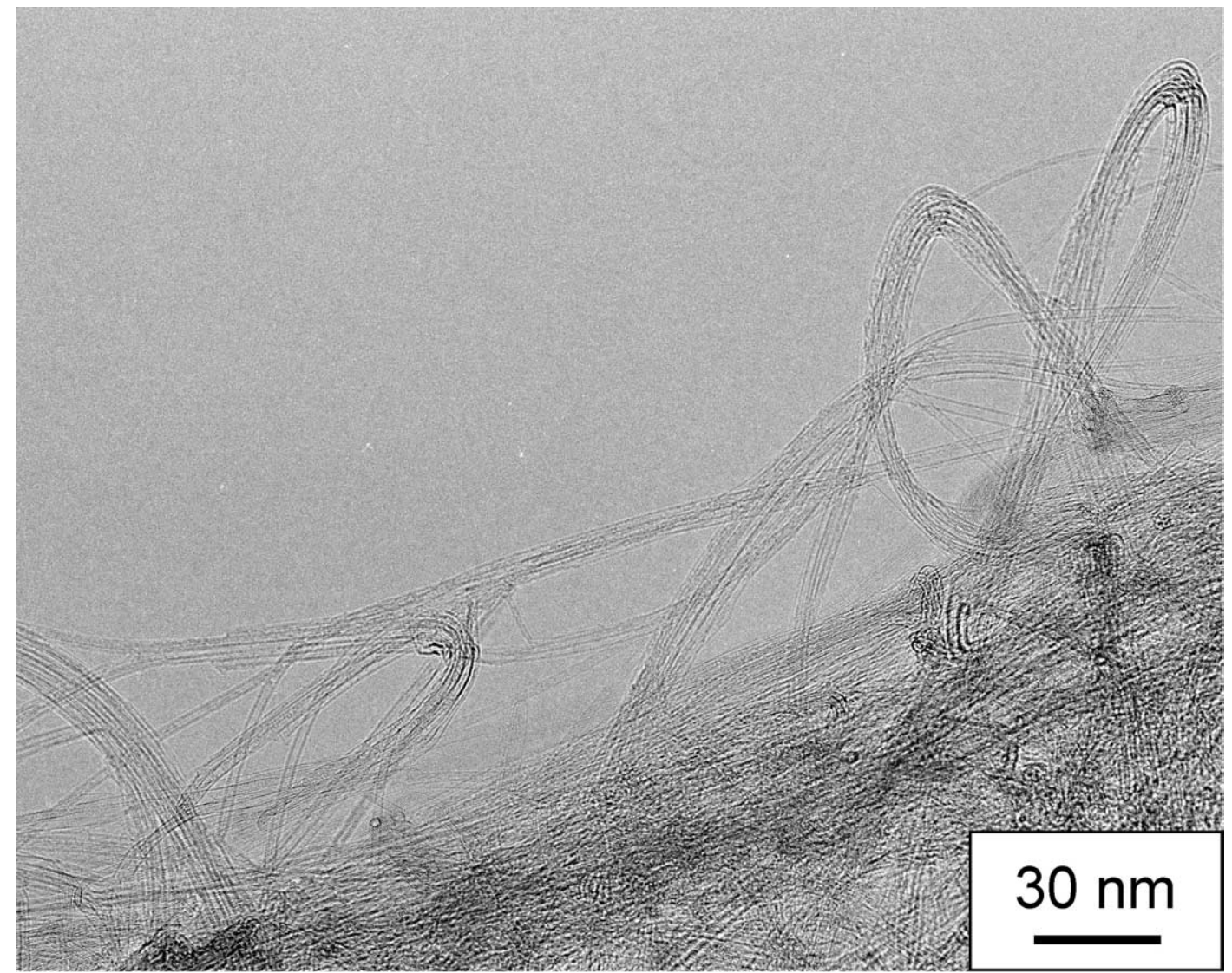

Fig. 4. 
Chemical Physics Letters, in press.

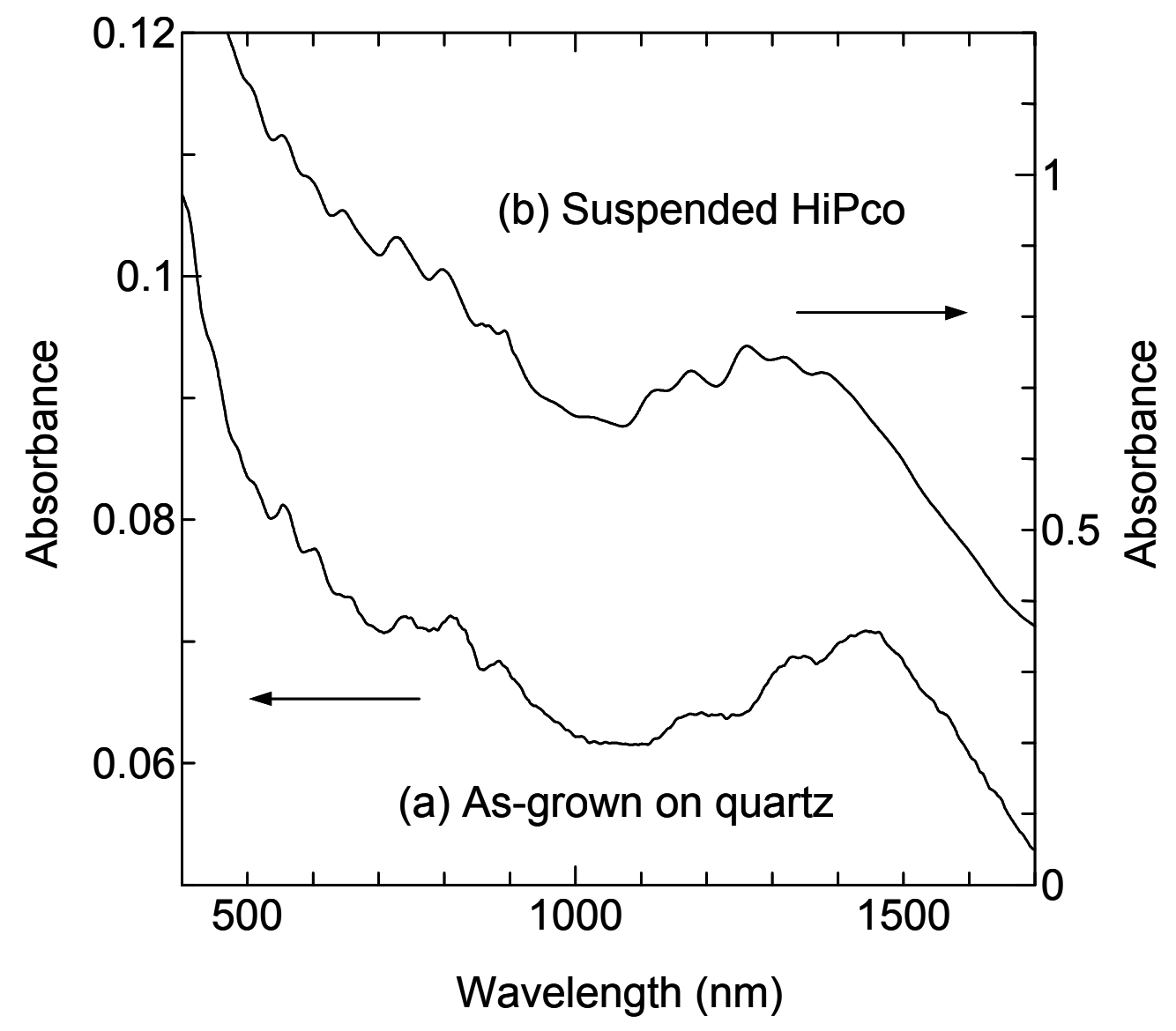

Fig. 5. 